\title{
Better quality of end-of-life care for persons with advanced dementia in nursing homes compared to hospitals: a Swedish national register study
}

\author{
Lisa Martinsson ${ }^{1 *}$ (D), Staffan Lundström ${ }^{2,3}$ and Johan Sundelöf ${ }^{4}$
}

\begin{abstract}
Background: Hospitalisation of patients with advanced dementia is generally regarded as less preferable compared to care at home or in a nursing home. For patients with other diagnoses, young age has been associated with better end-of-life care. However, studies comparing the quality of palliative care for persons with advanced dementia in hospitals and nursing homes are scarce. The aim of this study was to investigate whether quality of end-of-life care for patients with dementia depends on age, gender and place of death.

Methods: The Swedish Register of Palliative Care (SRPC) was used to identify patients who died from dementia in hospitals or nursing homes during a three-year period. The likelihood of death occurring at a hospital, based on age and gender differences, was calculated. Associations between 13 end-of-life care quality indicators collected from the SRPC and age, gender and place of care were examined in a logistic regression model.

Results: Death at a hospital was associated with poorer quality of end-of-life care for 10 of the 13 measured outcomes when compared to death at a nursing home, and with better quality according to two of the outcomes. Death at a hospital was more common for men compared to women and for younger patients compared to older. Receiving fluids intravenously or via enteral tube in the last $24 \mathrm{~h}$ of life was strongly associated with death at a hospital. Women were more likely to have their oral health assessed and less likely to have pressure ulcers at death. Eight of 12 end-of-life care outcomes showed better results for the age group 65 to 84 years compared to those 85 years or older.

Conclusions: Death in hospitals was associated with poorer quality of end-of-life care compared to death in nursing homes. Our data support the importance of advance care planning and individual assessments in nursing homes to avoid referral to hospitals during end of life. Despite established recommendations to avoid hospitalisation if possible, there were strong associations between younger age, male gender and hospitalisation in the end of life. Further studies are needed to investigate the role of socioeconomic factors in end-of-life care for this patient group.
\end{abstract}

Keywords: Dementia, Advanced dementia, Palliative care, End-of-life care, Hospitalisation, Gender, Age differences, Place of care

\footnotetext{
* Correspondence: lisa.martinsson@umu.se

'Department of Radiation Sciences, Umeå University, SE 90787 Umeå, Sweden

Full list of author information is available at the end of the article
}

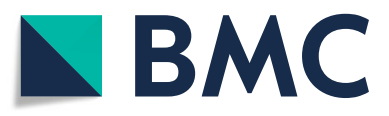

(c) The Author(s). 2020 Open Access This article is licensed under a Creative Commons Attribution 4.0 International License, which permits use, sharing, adaptation, distribution and reproduction in any medium or format, as long as you give appropriate credit to the original author(s) and the source, provide a link to the Creative Commons licence, and indicate if changes were made. The images or other third party material in this article are included in the article's Creative Commons licence, unless indicated otherwise in a credit line to the material. If material is not included in the article's Creative Commons licence and your intended use is not permitted by statutory regulation or exceeds the permitted use, you will need to obtain permission directly from the copyright holder. To view a copy of this licence, visit http://creativecommons.org/licenses/by/4.0/ The Creative Commons Public Domain Dedication waiver (http://creativecommons.org/publicdomain/zero/1.0/) applies to the data made available in this article, unless otherwise stated in a credit line to the data. 


\section{Background}

The white paper on dementia care from the European Association for Palliative Care concludes that "transfer to the hospital and the associated risks and benefits should be considered prudently in relation to the care goals and taking into account also the stage of the dementia" [1]. Despite these recommendations, hospitalisation of patients with advanced dementia is common [2].

A study by Mitchell et al. of predictors and risk factors associated with end-of-life stage in dementia clearly demonstrates the difficulties in identifying this stage [3]. In a Swedish study, dementia was a predictor for readmission to hospital within 90 days of discharge [4]. In a Belgian study, $20 \%$ of patients with dementia were hospitalised during the last month of life, and slightly fewer than $5 \%$ were cared for in an intensive care unit during the last month [5]. Pneumonia, febrile episodes, and eating problems are common for advanced dementia and are associated with high six-month mortality rates [6].

It is difficult to know who will benefit from hospitalisation and who will not. There is evidence that people with dementia can experience a range of adverse outcomes in hospitals; they are hospitalised longer, and more often readmitted to hospital within 3 months, compared to patients without dementia [7]. For patients dying from dementia-related causes, death at a hospital has been shown to be more common for men, married compared to non-married people, and patients 80 years or younger, compared to older patients [8]. According to Sampson et al., patients with dementia in hospitals were less often prescribed symptom management medication and less often admitted to palliative care compared to hospitalised patients without dementia [9].

Old age (regardless of diagnosis) seems to be a factor that influences the palliative care content, regarding both place of death and utilisation of care. Gielen et al. showed that older persons were more likely to die in a nursing home, less likely to be transferred between care settings and stayed fewer days in hospital [10]. Old age has been associated with a lower chance of receiving specialised palliative care [11]. In a Danish population study, women compared to men and patients less than 40 years old compared to 80 years and older were more likely to be admitted to specialised palliative care [12].

Some studies have shown that age has an impact on palliative care for patients with cancer: younger patients with cancer were more likely to receive specialised palliative care in Spain and Italy [13], old age was associated with higher probability of death in hospital [14], a study in Canada on women with breast cancer showed that young age was associated with lower probability of receiving a palliative care-oriented model of health care services [15] and older people who died of colorectal cancer had a lower chance of receiving a palliative care programme [16]. A study using data from the Swedish Register of Palliative Care (SRPC) showed that younger patients with cancer were more often informed about their disease; evaluated for pain and other symptoms; and prescribed medications as needed against pain, anxiety and nausea. Younger patients also more often received palliative care consultation, and their next of kin more often received information and were offered support after death of the patient, compared to those of older patients with cancer [17].

Studies comparing the quality of palliative care for persons with advanced dementia in hospitals and nursing homes are scarce.

\section{Aim}

The aim of this study was to investigate whether quality of end-of-life care for patients with dementia depends on age, gender and place of death.

\section{Methods \\ Planning and setting}

The SRPC collects data about quality of end-of-life care in Sweden using an end-of-life questionnaire (ELQ) [18]. The SRPC also contains data from the Swedish Cause of Death Register, which includes International Classification of Diseases 10 (ICD-10) codes describing underlying cause of death.

The SRPC was used to identify all patients who had died an expected death from dementia in hospitals (wards without palliative specialisation) and nursing homes (long- or short-term stay) during a three-year period from March 2012 to February 2015 and who had been reported to the SRPC. Death from dementia was defined as one of the ICD-10 codes F01, F02, F03 and G30, including subgroups, as the underlying cause of death. The study group was a subgroup of a larger cohort of patients who had died from dementia or cancer regardless of place of death, previously examined by the authors [19].

\section{Data analysis}

Patients were divided into three age groups (below 65 years, 65-84 and 85 and above). The limit of 65 years was chosen because this is the cut-off for early onset dementia [20] and also the Swedish retirement age, and a common age in Sweden to qualify for elderly care. The limit of 85 years has previously been used in the literature, for example, in the Leiden 85 plus study [21].

Distribution of age, gender and place of death (hospital or nursing home) for the study group was described. The likelihood of death at a hospital, dependent on age group and gender, was examined using multivariable logistic regression with the oldest age group as reference. End-of-life care outcomes for 13 quality indicators 
available in the SRPC database were compared between hospitals and nursing homes using chi-square tests. Items in the database about symptom occurrence and relief were not used, because of their limited validity [22]. The outcomes were then analysed with a multivariable logistic regression model with age, gender and place of death (hospital or nursing home) as independent variables. P-values below 0.05 were considered significant. Patients without next of kin were excluded when analysing the outcomes regarding next of kin. "Don't know" answers in the ELQ were considered missing data.

\section{Results}

A total of 18,610 adults who had died from dementia in hospitals or nursing homes were identified in the SRPC database during the study period. Out of these, 1397 persons were reported to have died unexpectedly, and 365 persons had "Don't know" reported regarding expected or unexpected death, resulting in missing data, and those were excluded. A total of 16,462 patients, 4752 with Alzheimer's disease and 11,710 with other or unspecified dementia, remained in the study. A smaller proportion, 967 patients (5.9\%), had died at a hospital, and 15,495 patients $(94.1 \%)$ had died in a nursing home. The mean age for the hospital group was 85.6 years (median 86, range 55-101). The mean age for the nursing home group was 87.4 (median 88 , range $41-110$ ). Death at a hospital compared to death in a nursing home was more likely for men than women and more likely in patients aged 65 to 84 years compared to patients 85 years and above (Table 1).

\section{End-of-life care outcomes in different care settings}

When not adjusting for age or gender, 10 of the 13 measured end-of-life care outcomes showed better outcomes in nursing homes compared to hospitals, while 2 outcomes were better in the hospital group (Table 2). Consultations of specialised palliative care teams were uncommon. The patients were more likely to have a documented decision to shift to end-of-life care in nursing homes as compared to hospitals. Giving information to next of kin about the transition to end-of-life care was more common in hospitals, but offering a follow-up talk to next of kin after death of the patient was more common in nursing homes.

Patients who died in nursing homes were more likely to be assessed for pain and other symptoms during the last week of life, to be prescribed PRN drugs against pain, nausea and anxiety, and to have someone present at the moment of death compared to patients who died in hospitals. Oral health assessments were equally common in hospitals and nursing homes. Pressure ulcers at the time of death were more common in hospitals. Fluids given via enteral tube or intravenously during the last $24 \mathrm{~h}$ of life were much more common in hospitals (36.5\%) than in nursing homes $(1.4 \%)$.

\section{Age and gender differences}

In the final model adjusted for gender, age groups and place of death, few gender differences remained. Women were more likely to have their oral health assessed and were less likely to have pressure ulcers at death compared to men. For the other 11 end-of-life care outcomes, no gender differences were found (Table 3).

In the final model, 8 out of 12 measured end-of-life care outcomes showed better outcomes for the age group of people 65 to 84 years old compared to those 85 years or older. Next of kin informed about transition to end-of-life care and next of kin offered a follow-up talk after death of the patient were the only two outcomes where the difference in outcome between the age groups was more than 5 percentage points. The other outcomes where the age group of 65 to 84 years showed small but significantly better outcomes compared to the oldest group were PRN drugs against pain, PRN drugs against anxiety, oral health assessed during the last week of life, documented decision to shift to end-of-life care, specialised palliative care team consulted and someone present at the moment of death. For the youngest age group (41 to 64 years), one outcome (next of kin offered

Table 1 Numbers and proportions of death at hospital per age and gender category, and likelihoods of death at hospital compared to nursing home, depending on age group and gender. Odds ratios (OR) with 95\% confidence intervals (Cl) and $p$-values are reported

\begin{tabular}{|c|c|c|c|c|c|}
\hline & Hospital deaths/all deaths (n) & Hospital deaths/all deaths (\%) & OR & $95 \% \mathrm{Cl}$ & $p$ \\
\hline \multicolumn{6}{|c|}{ Age groups in years } \\
\hline $41-64$ & $8 / 95$ & 8.4 & 1.436 & $0.688-2.995$ & 0.335 \\
\hline $65-84$ & $418 / 5112$ & 8.2 & 1.528 & $1.335-1.748$ & $<0.001$ \\
\hline $85-110$ & $541 / 11,255$ & 4.8 & $\operatorname{Ref}^{a}$ & & \\
\hline \multicolumn{6}{|l|}{ Gender } \\
\hline Women & $432 / 11,120$ & 3.9 & 0.387 & $0.338-0.442$ & $<0.001$ \\
\hline Men & $535 / 5342$ & 10.0 & $\operatorname{Ref}^{a}$ & & \\
\hline
\end{tabular}

\footnotetext{
${ }^{a}$ Reference
} 
Table 2 End-of-life care outcomes for 13 quality indicators in hospitals and nursing homes. Differences in proportions between hospitals and nursing homes are calculated with chi-square test

\begin{tabular}{|c|c|c|c|c|c|c|}
\hline \multirow[t]{2}{*}{ Quality indicators } & \multirow{2}{*}{$\begin{array}{l}\text { Missing } \\
\text { (n) }\end{array}$} & \multicolumn{2}{|l|}{ Hospital } & \multicolumn{2}{|l|}{ Nursing home } & \multirow[t]{2}{*}{$p$} \\
\hline & & $\mathrm{n}$ & $\%$ & $n$ & $\%$ & \\
\hline Specialised palliative care team consulted & 0 & $22 / 967$ & 2.3 & $192 / 15,495$ & 1.2 & 0.006 \\
\hline Documented decision to shift to end-of-life care & 1754 & $731 / 897$ & 81.5 & $12,460 / 13,811$ & 90.2 & $<0.001$ \\
\hline Next of kin given information about transition to end-of-life care & 1284 & $714 / 878$ & 81.3 & $10,215 / 14,300$ & 71.4 & $<0.001$ \\
\hline Next of kin offered a follow-up talk after death of the patient & 2968 & $263 / 617$ & 42.6 & $9697 / 12,877$ & 75.3 & $<0.001$ \\
\hline Pain assessed and documented during the last week of life & 619 & $140 / 861$ & 16.3 & $4838 / 14,982$ & 32.3 & $<0.001$ \\
\hline Symptoms other than pain assessed during the last week of life & 853 & $79 / 802$ & 9.9 & $2773 / 14,807$ & 18.7 & $<0.001$ \\
\hline Oral health assessed during the last week of life & 1280 & $630 / 824$ & 76.5 & $10,992 / 14,358$ & 76.6 & 0.947 \\
\hline Prescription of PRN drugs against pain & 62 & $839 / 949$ & 88.4 & $14,461 / 15,451$ & 93.6 & $<0.001$ \\
\hline Prescription of PRN drugs against nausea & 225 & 398/927 & 42.9 & $9606 / 15,310$ & 62.7 & $<0.001$ \\
\hline Prescription of PRN drugs against anxiety & 133 & 705/939 & 75.1 & $13,171 / 15,390$ & 85.6 & $<0.001$ \\
\hline Pressure ulcer at death & 157 & 219/908 & 24.1 & $2278 / 15,397$ & 14.8 & $<0.001$ \\
\hline Someone present at the moment of death & 291 & $652 / 936$ & 69.7 & $13,711 / 15,235$ & 90.0 & $<0.001$ \\
\hline Fluids via enteral tube or intravenously during last $24 \mathrm{~h}$ of life & 55 & $344 / 943$ & 36.5 & $220 / 15,464$ & 1.4 & $<0.001$ \\
\hline
\end{tabular}

a follow-up talk after death of the patient) was significantly higher than the oldest age group (Table 3 ).

Three end-of-life care outcomes (PRN drugs against nausea, pain assessed and documented during the last week of life and symptoms other than pain assessed during the last week of life) showed neither gender nor age differences (Table 3).

Because of the low number of patients receiving fluids via enteral tube or intravenously during last $24 \mathrm{~h}$ of life in nursing homes, only hospital deaths were included in the logistic regression model adjusted for age and gender. The model showed no age or gender differences regarding the probability of receiving fluids (Table 4).

\section{Discussion}

In this national register study of 16,462 adults who died an expected death from dementia in hospitals or nursing homes we have shown that death at a hospital was associated with poorer quality of end-of-life care compared to death at a nursing home for all but three of the measured outcomes. Also, place of death was shown to have a larger impact on end-of-life care outcomes for patients dying expectedly from dementia, compared to age and gender. To the best of our knowledge, this is the largest study so far investigating the quality of end-of-life care in advanced dementia in nursing homes and hospitals, and the only one examining a wide range of qualityrelated care outcomes.

There are recommendations to, if possible, avoid hospitalisation for patients with advanced dementia [1]. In addition acute settings are not suitable for persons with dementia [23]. Despite this, little is known about where patients with dementia wish to be cared for at the end of life. Also, their families' opinions and views of the healthcare staff are not fully known [24]. However, carers may be more satisfied with the care given if the patient had died at home compared to having died in a hospital [25].

A marked difference between deaths in nursing homes and hospitals was that $30 \%$ died without someone present in hospitals, while the corresponding figure for nursing homes was $10 \%$, although all deaths were reported as having been expected. It is unclear whether this difference is due to lack of resources or if it could be addressed with better routines and awareness of endof-life care.

Also, there was a pronounced difference between hospitals and nursing homes concerning administration of fluids via enteral tube or intravenously during the last $24 \mathrm{~h}$ of life. Over one third of the patients who died an expected death in hospitals received fluids, compared with only $1.4 \%$ in nursing homes. According to the white paper on dementia care from the European Association for Palliative Care, permanent enteral tube nutrition may not be beneficial and should as a rule be avoided in dementia, and hydration is inappropriate in the dying phase [1]. The current Swedish national guidelines for palliative end-of-life care advise against routine administration of fluids intravenously or via enteral tubes for most patients who are expected to die within a short timeframe [26].

This study found strong associations between younger age, male gender and hospitalisation for patients dying an expected death from dementia. These findings are in line with the findings from Reyniers et al. [8] and also in line with Houttekier et al., who found that women and 
Table 3 Logistic regression model comparing 12 end-of-life care outcomes for three age groups (in years) and for men and women, adjusted for place of death (hospital/nursing home). Odds ratios (OR) and 95\% confidence intervals (Cl) are reported

\begin{tabular}{|c|c|c|c|c|c|}
\hline & $n$ & $\%$ & $\mathrm{OR}$ & $95 \% \mathrm{Cl}$ & $p$ \\
\hline \multicolumn{6}{|c|}{ PRN drugs against pain } \\
\hline \multicolumn{6}{|l|}{ Age } \\
\hline $41-64$ & $88 / 95$ & 92.6 & 1.006 & $0.464-2.185$ & 0.987 \\
\hline $65-84$ & $4799 / 5086$ & 94.4 & 1.335 & $1.159-1.537$ & $<0.001$ \\
\hline $85-110$ & $10,413 / 11,219$ & 92.8 & $\operatorname{Ref}^{a}$ & & \\
\hline \multicolumn{6}{|l|}{ Gender } \\
\hline Women & $10,342 / 11,081$ & 93.3 & 1.006 & $0.880-1.149$ & 0.931 \\
\hline Men & $4958 / 5319$ & 93.2 & $\operatorname{Ref}^{a}$ & & \\
\hline \multicolumn{6}{|c|}{ PRN drugs against nausea } \\
\hline \multicolumn{6}{|l|}{ Age } \\
\hline $41-64$ & $59 / 94$ & 62.8 & 1.108 & $0.726-1.691$ & 0.636 \\
\hline $65-84$ & $3131 / 5037$ & 62.2 & 1.069 & $0.997-1.147$ & 0.060 \\
\hline $85-110$ & $6814 / 11,106$ & 61.4 & $\operatorname{Ref}^{a}$ & & \\
\hline \multicolumn{6}{|l|}{ Gender } \\
\hline Women & $6832 / 10,984$ & 62.2 & 1.038 & $0.969-1.113$ & 0.285 \\
\hline Men & $3172 / 5253$ & 60.4 & $\operatorname{Ref}^{a}$ & & \\
\hline \multicolumn{6}{|c|}{ PRN drugs against anxiety } \\
\hline \multicolumn{6}{|l|}{ Age } \\
\hline $41-64$ & $79 / 94$ & 84.0 & 0.991 & $0.568-1.730$ & 0.975 \\
\hline $65-84$ & $4342 / 5063$ & 85.8 & 1.127 & $1.024-1.240$ & 0.014 \\
\hline $85-110$ & $9455 / 11,172$ & 84.6 & $\operatorname{Ref}^{\mathrm{a}}$ & & \\
\hline \multicolumn{6}{|l|}{ Gender } \\
\hline Women & $9405 / 11,041$ & 85.2 & 1.017 & $0.926-1.116$ & 0.728 \\
\hline Men & $4471 / 5288$ & 84.5 & $\operatorname{Ref}^{a}$ & & \\
\hline \multicolumn{6}{|c|}{ Pain assessed and documented during the last week of life } \\
\hline \multicolumn{6}{|l|}{ Age } \\
\hline $41-64$ & 29/93 & 31.2 & 1.025 & $0.658-1.595$ & 0.914 \\
\hline $65-84$ & $1550 / 4916$ & 31.5 & 1.039 & $0.965-1.118$ & 0.313 \\
\hline $85-110$ & $3399 / 10,834$ & 31.4 & $\operatorname{Ref}^{\mathrm{a}}$ & & \\
\hline \multicolumn{6}{|l|}{ Gender } \\
\hline Women & $3428 / 10,726$ & 32.0 & 1.042 & $0.968-1.121$ & 0.277 \\
\hline Men & $1550 / 5117$ & 30.3 & $\operatorname{Ref}^{a}$ & & \\
\hline \multicolumn{6}{|c|}{ Symptoms other than pain assessed during the last week of life } \\
\hline \multicolumn{6}{|l|}{ Age } \\
\hline $41-64$ & $22 / 87$ & 25.3 & 1.572 & $0.966-2.560$ & 0.069 \\
\hline $65-84$ & $890 / 4830$ & 18.4 & 1.049 & $0.960-1.146$ & 0.294 \\
\hline $85-110$ & 1940/10,692 & 18.1 & $\operatorname{Ref}^{a}$ & & \\
\hline \multicolumn{6}{|l|}{ Gender } \\
\hline Women & $1984 / 10,584$ & 18.7 & 1.080 & $0.988-1.181$ & 0.091 \\
\hline Men & $868 / 5025$ & 17.3 & $\operatorname{Ref}^{a}$ & & \\
\hline \multicolumn{6}{|c|}{ Oral health assessed during the last week of life } \\
\hline \multicolumn{6}{|l|}{ Age } \\
\hline $41-64$ & $78 / 93$ & 83.9 & 1.712 & $0.983-2.981$ & 0.058 \\
\hline
\end{tabular}


Table 3 Logistic regression model comparing 12 end-of-life care outcomes for three age groups (in years) and for men and women, adjusted for place of death (hospital/nursing home). Odds ratios (OR) and 95\% confidence intervals (CI) are reported (Continued)

\begin{tabular}{|c|c|c|c|c|c|}
\hline & $n$ & $\%$ & OR & $95 \% \mathrm{Cl}$ & $p$ \\
\hline $65-84$ & $3696 / 4730$ & 78.1 & 1.162 & $1.069-1.263$ & $<0.001$ \\
\hline $85-110$ & $7848 / 10,359$ & 75.8 & $\operatorname{Ref}^{a}$ & & \\
\hline \multicolumn{6}{|l|}{ Gender } \\
\hline Women & $7923 / 10,286$ & 77.0 & 1.112 & $1.025-1.206$ & 0.010 \\
\hline Men & $3699 / 4896$ & 75.6 & $\operatorname{Ref}^{\mathrm{a}}$ & & \\
\hline
\end{tabular}

Next of kin informed about transition to end-of-life care

Age

$\begin{array}{lll}41-64 & 72 / 90 & 80.0 \\ 65-84 & 3549 / 4733 & 75.0 \\ 85-110 & 7308 / 10,355 & 70.6 \\ \text { Gender } & \\ \text { Women } & 7331 / 10,274 & 71.4 \\ \text { Men } & 3598 / 4904 & 73.4\end{array}$

80.0

75.0

70.6

71.4

73.4

Next of kin offered a follow-up talk after death of the patient

Age

$\begin{array}{ll}41-64 & 69 / 84 \\ 65-84 & 3119 / 4152 \\ 85-110 & 6772 / 9258 \\ \text { Gender } & \\ \text { Women } & 6828 / 9217 \\ \text { Men } & 3132 / 4277\end{array}$

Documented decision to shift to end-of-life care

Age

$\begin{array}{ll}41-64 & 75 / 84 \\ 65-84 & 4145 / 4574 \\ 85-110 & 8971 / 10,050\end{array}$

Gender

$\begin{array}{ll}\text { Women } & 8934 / 9924 \\ \text { Men } & 4257 / 4784\end{array}$

Specialised palliative care team consulted

Age

$\begin{array}{ll}41-64 & 3 / 95 \\ 65-84 & 84 / 5112 \\ 85-110 & 127 / 11,255\end{array}$

Gender

$\begin{array}{ll}\text { Women } & 147 / 11,120 \\ \text { Men } & 67 / 5342\end{array}$

Someone present at the moment of death Age

$\begin{array}{ll}41-64 & 85 / 93 \\ 65-84 & 4554 / 5043 \\ 85-110 & 9724 / 11,035\end{array}$

$85-110$

9724/11,035
1.630

0.970-2.739

0.065

1.224

1.131-1.325

$<0.001$

$\operatorname{Ref}^{a}$

0.959

0.887-1.036

0.289

$\operatorname{Ref}^{a}$

1.776

$1.005-3.140$

0.048

1.161

$1.064-1.265$

0.001

$\operatorname{Ref}^{a}$

0.983

0.903-1.071

0.701

$\operatorname{Ref}^{a}$

1.066

$0.531-2.141$

0.858

1.216

1.079-1.371

0.001

$\operatorname{Ref}^{a}$

1.083

$0.966-1.215$

0.171

$\operatorname{Ref}^{a}$

2.895

0.902-9.293

0.074

1.461

1.103-1.937

0.008

$\operatorname{Ref}^{\mathrm{a}}$

1.181

$0.877-1.590$

0.274

Ref $^{a}$

1.505

0.720-3.147

0.277

1.340

1.197-1.501

$<0.001$
$\operatorname{Ref}^{\mathrm{a}}$ 
Table 3 Logistic regression model comparing 12 end-of-life care outcomes for three age groups (in years) and for men and women, adjusted for place of death (hospital/nursing home). Odds ratios (OR) and 95\% confidence intervals (Cl) are reported (Continued)

\begin{tabular}{|c|c|c|c|c|c|}
\hline & $n$ & $\%$ & $\mathrm{OR}$ & $95 \% \mathrm{Cl}$ & $p$ \\
\hline \multicolumn{6}{|l|}{ Gender } \\
\hline Women & $9691 / 10,915$ & 88.8 & 0.904 & $0.811-1.008$ & 0.070 \\
\hline Men & $4672 / 5256$ & 88.9 & $\operatorname{Ref}^{a}$ & & \\
\hline \multicolumn{6}{|c|}{ Pressure ulcers at death } \\
\hline \multicolumn{6}{|l|}{ Age } \\
\hline $41-64$ & $13 / 94$ & 13.8 & 0.829 & $0.460-1.496$ & 0.534 \\
\hline $65-84$ & $767 / 5055$ & 15.2 & 0.943 & $0.859-1.036$ & 0.221 \\
\hline $85-110$ & $1717 / 11,156$ & 15.4 & $\operatorname{Ref}^{a}$ & & \\
\hline \multicolumn{6}{|l|}{ Gender } \\
\hline Women & $1613 / 11,031$ & 14.6 & 0.876 & $0.799-0.960$ & 0.005 \\
\hline Men & $884 / 5274$ & 16.8 & $\operatorname{Ref}^{a}$ & & \\
\hline
\end{tabular}

${ }^{a}$ Reference

patients with higher age were more likely to die in nursing homes than in hospitals [27]. A possible explanation for male gender being a risk factor for hospitalisation could be that men are more often cared for by their spouse at home compared to women, resulting in hospitalisation in case of acute deterioration. Marital status has also been shown as a predictor for hospitalisation [8] but could not be examined in this study because the SRPC database does not contain this data.

Identifying the patient as being in the dying phase can be a key factor in avoiding hospitalisations that do not benefit the patient. Several prognostic tools for survival estimates have been published, but it still remains a challenge to identify the late palliative phase of dementia [3, 28, 29].

Advance care planning has been shown to improve consistency of care with the patients' goals [30] and may be a way to reduce unwanted hospitalisations and

Table 4 Logistic regression model comparing the probability of receiving fluids via enteral tube or intravenously during the last $24 \mathrm{~h}$ of life for three age groups (in years) and for men and women, including only hospital deaths, not adjusted for place of death. Odds ratios (OR) and 95\% confidence intervals (CI) are reported

\begin{tabular}{|c|c|c|c|c|c|}
\hline & $n$ & $\%$ & OR & $95 \% \mathrm{Cl}$ & $p$ \\
\hline \multicolumn{6}{|c|}{ Fluids via enteral tube or intravenously during the last $24 \mathrm{~h}$ of life } \\
\hline \multicolumn{6}{|l|}{ Age } \\
\hline $41-64$ & $5 / 8$ & 62.5 & 2.715 & $0.641-11.498$ & 0.175 \\
\hline $65-84$ & $140 / 406$ & 34.5 & 0.856 & $0.653-1.124$ & 0.264 \\
\hline $85-110$ & 199/529 & 37.6 & $\operatorname{Ref}^{a}$ & & \\
\hline \multicolumn{6}{|l|}{ Gender } \\
\hline Women & $145 / 419$ & 34.6 & 0.851 & $0.650-1.115$ & 0.241 \\
\hline Men & 199/524 & 38.0 & $\operatorname{Ref}^{a}$ & & \\
\hline
\end{tabular}

\footnotetext{
${ }^{a}$ Reference
}

increase the use of palliative care [30]. A do-nothospitalise order has been shown to reduce the probability of acute hospitalisation [31], and advance directives have been shown to predict less time in hospital for patients with dementia [26]. In the SRPC database, there is no information about these types of orders or why the patient was sent to hospital. Also, advance directives are not legally binding in Sweden. Referral to hospital of a patient may be based on the conclusion that it will be better for the patient or that it is not possible to properly care for the patient in the home care setting or at the nursing home. If the aim is high quality end-of-life care, it may be better for the patient to be taken care of at the nursing home, as the staff know how to communicate and meet the needs of persons with severe dementia. This study demonstrates that a majority of patients with dementia were given end-of-life care in the nursing home, indicating that a majority of patients suffering from dementia can be managed in nursing homes during end of life.

A strength of our study is the large sample size and the population-based data. Despite a large sample size, the group of patients below 65 years of age who had died in a hospital was small, making it hard to draw further conclusions for this subgroup. In the future, it would be interesting to further examine which patients with a dementia diagnosis are hospitalised in the end of life and why. This could possibly be achieved by collecting data, including socioeconomic factors, from medical records and/or the patient registry at the National Board of Health and Welfare.

\section{Conclusions}

Death in hospitals was associated with poorer quality of end-of-life care compared to death in nursing homes. 
Our data support the importance of advance care planning and individual assessments in nursing homes to avoid referral to hospitals during end of life. Despite established recommendations to avoid hospitalisation if possible, there were strong associations between younger age, male gender and hospitalisation in the end of life. Further studies are needed to investigate the role of socioeconomic factors in end-of-life care for this patient group.

\section{Abbreviations}

Cl: Confidence interval; ELQ: End-of-life questionnaire; ICD-10: International Classification of Diseases 10; OR: Odds ratio; PRN: Pro re nata; SRPC: Swedish Register of Palliative Care

\section{Acknowledgements}

The authors wish to thank Björn Tavelin at RCC, Umeå, Sweden, for statistical guidance.

\section{Authors' contributions}

LM, SL and JS planned the study. LM analysed the register data statistically, and $L M, S L$ and JS together interpreted the results. LM wrote the first manuscript draft and SL and JS made critical revisions. All authors approved the final version.

\section{Funding}

This study was supported by the Swedish research foundation Stiftelsen Olle Engqvist byggmästare (grant number 183-435, http://engkviststiftelserna.se/) and Västerbotten County Council, Sweden. The funder had no role in study design, data collection, data analysis or data interpretation. Open access funding provided by Umea University.

\section{Availability of data and materials}

The dataset contains personally identifying information, such as personal identity numbers, and potentially identifying information, such as date of death, and therefore is subject to ethical and legal restrictions on public sharing. We cannot share the dataset, which is on individual level, because it is not permitted according to the laws that apply in Sweden.

\section{Ethics approval and consent to participate}

The working procedure and study design were examined by the Regional Ethical Review Board in Umeå, Sweden, and they had no ethical objections to the study (registration number 2017/11-31). Data were collected after death of the patients.

\section{Consent for publication}

Data are only reported in aggregate and cannot be attributed to individuals.

\section{Competing interests}

The authors report no competing interests.

\begin{abstract}
Author details
'Department of Radiation Sciences, Umeå University, SE 90787 Umeå, Sweden. ${ }^{2}$ Department of Palliative Medicine, Stockholms Sjukhem Foundation, SE 11219 Stockholm, Sweden. ${ }^{3}$ Department of Oncology-Pathology, Karolinska Institutet, SE 17177 Stockholm, Sweden. ${ }^{4}$ Betaniastiftelsen (non-profit organisation), SE 11620 Stockholm, Sweden.
\end{abstract}

Received: 8 June 2020 Accepted: 13 August 2020

Published online: 26 August 2020

\section{References}

1. van der Steen JT, Radbruch L, Hertogh CM, et al. White paper defining optimal palliative care in older people with dementia: a Delphi study and recommendations from the European Association for Palliative Care. Palliat Med. 2014;28(3):197-209

2. Lamberg JL, Person CJ, Kiely DK, et al. Decisions to hospitalize nursing home residents dying with advanced dementia. J Am Geriatr Soc. 2005;
53(8):1396-401. https://doi.org/10.1111/j.1532-5415.2005.53426.x [published Online First: 2005/08/05]

3. Mitchell SL, Miller SC, Teno JM, et al. The advanced dementia prognostic tool: a risk score to estimate survival in nursing home residents with advanced dementia. J Pain Symptom Manage. 2010;40(5):639-51. https://doi.org/10. 1016/j.jpainsymman.2010.02.014 [published Online First: 2010/07/14].

4. Stäck P, Forsberg B, Högberg M, et al. Originalstudie-Risken för akut återinläggning kan förutsägas. Tidigare vårdkonsumtionsmönster och vissa diagnoser starkt predicerande. Läkartidningen. 2012;109(48):2211.

5. Houttekier D, Vandervoort A, Van den Block L, et al. Hospitalizations of nursing home residents with dementia in the last month of life: results from a nationwide survey. Palliat Med. 2014;28(9):1110-7. https://doi.org/10.1177/ 0269216314535962 [published Online First: 2014/05/29].

6. Mitchell SL, Teno JM, Kiely DK, et al. The clinical course of advanced dementia. New Eng J Med. 2009:361(16):1529-38.

7. Draper B, Karmel R, Gibson D, et al. The Hospital Dementia Services Project: age differences in hospital stays for older people with and without dementia. Int Psychogeriatr. 2011;23(10):1649-58. https://doi.org/10.1017/ s1041610211001694 [published Online First: 2011/09/10].

8. Reyniers T, Deliens L, Pasman HR, et al. International variation in place of death of older people who died from dementia in 14 European and nonEuropean countries. J Am Med Dir Assoc. 2015;16(2):165-71. https://doi.org/ 10.1016/j.jamda.2014.11.003 [published Online First: 2014/12/30].

9. Sampson EL, Gould V, Lee D, et al. Differences in care received by patients with and without dementia who died during acute hospital admission: a retrospective case note study. Age Ageing. 2006;35(2):187-9. https://doi.org/ 10.1093/ageing/afj025 [published Online First: 2006/01/13].

10. Gielen B, Remacle A, Mertens R. Patterns of health care use and expenditure during the last 6 months of life in Belgium: differences between age categories in cancer and non-cancer patients. Health Policy. 2010;97(1):5361. https://doi.org/10.1016/j.healthpol.2010.03.002 [published Online First: 2010/04/03].

11. Abarshi E, Echteld MA, Van den Block L, et al. The oldest old and GP end-oflife care in the Dutch community: a nationwide study. Age Ageing. 2010; 39(6):716-22. https://doi.org/10.1093/ageing/afq097 [published Online First: 2010/09/08].

12. Adsersen $M$, Thygesen $L C$, Jensen $A B$, et al. Is admittance to specialised palliative care among cancer patients related to sex, age and cancer diagnosis? A nation-wide study from the Danish Palliative Care Database (DPD). BMC Palliat Care. 2017;16(1):21. https://doi.org/10.1186/s12904-0170194-z [published Online First: 2017/03/24].

13. Pivodic $\mathrm{L}$, Pardon $\mathrm{K}$, Van den Block $\mathrm{L}$, et al. Palliative care service use in four European countries: a cross-national retrospective study via representative networks of general practitioners. Plos One. 2013;8(12):e84440. https://doi. org/10.1371/journal.pone.0084440 [published Online First: 2014/01/05].

14. Gao W, Ho YK, Verne J, et al. Changing patterns in place of cancer death in England: a population-based study. PLoS Med. 2013;10(3):e1001410. https:/ doi.org/10.1371/journal.pmed.1001410 [published Online First: 2013/04/05].

15. Gagnon B, Mayo NE, Hanley J, et al. Pattern of care at the end of life: does age make a difference in what happens to women with breast cancer? J Clin Oncol. 2004;22(17):3458-65. https://doi.org/10.1200/jco.2004.06.111 [published Online First: 2004/07/28].

16. Maddison AR, Asada Y, Burge $F$, et al. Inequalities in end-of-life care for colorectal cancer patients in Nova Scotia, Canada. J Palliat Care. 2012;28(2): 90-6 [published Online First: 2012/08/07].

17. Lindskog $M$, Tavelin B, Lundstrom S. Old age as risk indicator for poor endof-life care quality - a population-based study of cancer deaths from the Swedish Register of Palliative Care. Eur J Cancer. 2015;51(10):1331-9. https:// doi.org/10.1016/j.ejca.2015.04.001 [published Online First: 2015/05/11].

18. Lundström S, Axelsson B, Heedman PA, et al. Developing a national quality register in end-of-life care: the Swedish experience. Palliat Med. 2012;26(4): 313-21. https://doi.org/10.1177/0269216311414758 [published Online First: 2011/07/09].

19. Martinsson L, Lundström S, Sundelöf J. Quality of end-of-life care in patients with dementia compared to patients with cancer: a population-based register study. PLoS One. 2018;13(7):e0201051.

20. McMurtray A, Clark DG, Christine D, et al. Early-onset dementia: frequency and causes compared to late-onset dementia. Dement Geriatr Cogn Disord. 2006;21(2):59-64.

21. van Peet PG, Drewes YM, de Craen AJM, et al. Prognostic value of cardiovascular disease status: the Leiden 85-plus study. Age (Dordrecht, 
Netherlands). 2013;35(4):1433-44. https://doi.org/10.1007/s11357-012-9443-5 [published Online First: 07/04].

22. Martinsson L, Heedman PA, Lundstrom S, et al. Improved data validity in the Swedish Register of Palliative Care. PloS One. 2017;12(10):e0186804. https://doi.org/10.1371/journal.pone.0186804 [published Online First: 2017/ 10/20].

23. Dewing J, Dijk S. What is the current state of care for older people with dementia in general hospitals? A literature review. Dementia (London, England). 2016;15(1):106-24. https://doi.org/10.1177/1471301213520172 [published Online First: 2014/01/25].

24. Badrakalimuthu V, Barclay S. Do people with dementia die at their preferred location of death? A systematic literature review and narrative synthesis. Age Ageing. 2014;43(1):13-9. https://doi.org/10.1093/ageing/aft151 [published Online First: 2013/10/17].

25. Volicer L, Hurley AC, Blasi ZV. Characteristics of dementia end-of-life care across care settings. Am J Hosp Palliat Care. 2003;20(3):191-200. https://doi. org/10.1177/104990910302000307 [published Online First: 2003/06/06]

26. Houttekier D, Cohen J, Bilsen J, et al. Place of death of older persons with dementia: study in five European countries. J Am Geriatr Soc. 2010;58(4): 751-6. https://doi.org/10.1111/j.1532-5415.2010.02771.x [published Online First: 2010/04/20].

27. Regionala cancercentrum i samverkan [Regional cancer centre in collaboration]. Nationellt vårdprogram Palliativ vård i livets slutskede [National guidelines for palliative end-of-life care]. Sweden: Regionala cancercentrum i samverkan [Regional cancer center in collaboration]; 2016. Available from: [https://www.cancercentrum.se/samverkan/vara-uppdrag/ palliativ-vard/vardprogram/gallande-vardprogram/14.-omvardnad-i-livetsslutskede\#14.8-vatska-och-naring].

28. Brown MA, Sampson EL, Jones $\mathrm{L}$, et al. Prognostic indicators of 6-month mortality in elderly people with advanced dementia: a systematic review. Palliat Med. 2013;27(5):389-400. https://doi.org/10.1177/0269216312465649 [published Online First: 2012/11/24].

29. Lee KC, Hsu WH, Chou PH, et al. Estimating the survival of elderly patients diagnosed with dementia in Taiwan: A longitudinal study. Plos One. 2018; 13(7):e0178997. https://doi.org/10.1371/journal.pone.0178997 [published Online First: 2018/07/26]

30. Rietjens JAC, Sudore RL, Connolly M, et al. Definition and recommendations for advance care planning: an international consensus supported by the European Association for Palliative Care. Lancet Oncol. 2017;18(9):e543-e51. https://doi.org/10.1016/s1470-2045(17)30582-x [published Online First: 2017/ 09/09].

31. Givens JL, Selby K, Goldfeld KS, et al. Hospital transfers of nursing home residents with advanced dementia. J Am Geriatr Soc. 2012;60(5):905-9. https://doi.org/10.1111/j.1532-5415.2012.03919.x [published Online First: 2012/03/21]

\section{Publisher's Note}

Springer Nature remains neutral with regard to jurisdictional claims in published maps and institutional affiliations.

Ready to submit your research? Choose BMC and benefit from:

- fast, convenient online submission

- thorough peer review by experienced researchers in your field

- rapid publication on acceptance

- support for research data, including large and complex data types

- gold Open Access which fosters wider collaboration and increased citations

- maximum visibility for your research: over $100 \mathrm{M}$ website views per year

At BMC, research is always in progress.

Learn more biomedcentral.com/submissions 